\title{
Práticas corporais em Juiz de Fora (|876-19|5)
}

Carlos Fernando Ferreira da Cunha Junior"

Resumo: Até a década de 1920, Juiz de Fora era considerada a principal cidade de Minas Gerais, por sua pujança econômica e por seu desenvolvimento cultural. A cidade está localizada próxima ao Rio de Janeiro e vivenciou um intenso processo de modernização a partir da segunda metade do século XIX. Nosso trabalho analisa o desenvolvimento das práticas corporais em Juiz de Fora (MG), entre 1876 e 1915, através do principal periódico publicado na cidade, o jornal $O$ Pharol. Símbolos da modernidade, as práticas corporais foram desenvolvidas em Juiz de Fora, na perspectiva da educação para a saúde (higiene), bem como na lógica do divertimento e do espetáculo.

Palavras-chave: práticas corporais; história; Juiz de Fora.

\section{Body practices in Juiz de Fora (1876-1915)}

Abstract: Until the 1920s, Juiz de Fora was considered the main city of Minas Gerais for its economic strength and cultural development. The city is located next to Rio de Janeiro and experienced an intense process of modernization as from the second half of the nineteenth century. Our work explores the development of body practices in Juiz de Fora (MG) between 1876 and 1915, through the major tabloid published in the city, the newspaper entitled ' $O$ Pharol'. Symbols of modernity, the body practices were developed in Juiz de Fora under the principles of health education (hygiene), and the logics of fun and entertainment.

Key words: physical activities; history; Juiz de Fora.

\section{Introdução}

As preocupações com o corpo ocupam lugar de destaque na sociedade contemporânea. As práticas corporais ganharam o cotidiano de grande parte da população por motivos variados: saúde, estética, socialização, ludicidade, entre outros. Academias de ginástica, natação, ioga, pilates; clubes esportivos; instalações de rua para caminhada e exercícios analíticos; campos de futebol e quadras das escolas são exemplos de espaços que hoje são comuns na vida de várias cidades brasileiras.

Professor e coordenador do Grupo de Estudos e Pesquisas em História da Educação Física e do Esporte (GEPHEFE) da Universidade Federal de Juiz de Fora, MG, Brasil. carlos.fernando@ uff.edu.br

Pesquisa financiada com recursos da Fapemig 
As práticas corporais começaram a ser valorizadas em terras brasileiras especialmente a partir da segunda metade do século XIX, período em que o País experimentou intenso processo de modernização.

O estabelecimento da relação entre saúde e corpos em movimento se dá e se acirra no decorrer do processo de construção e consolidação do ideário e imaginário da modernidade. As atividades físicas em geral, em especial os esportes, articuladas com as ideias de espetáculo e consumo, se tornaram elementos-chave no forjar de uma nova sensibilidade pública que hoje nos parece inequívoca (Melo, 2006).

Esse período histórico que chamamos de modernidade ${ }^{1}$ se expressa de modo mais efetivo no Brasil a partir da segunda metade do século XIX. No entanto, identificamos esse movimento na Europa no decorrer do século XVIII, quando um novo modelo econômico baseado na fábrica, a efetivação do Estado-Nação e a ascensão da burguesia como classe social romperam com o passado.

Cidades como Londres, Paris, Chicago e Nova York inauguraram modelos de urbanidade por meio de reformas e de difusão de novas ideias, conceitos e sensibilidades. Logo essas cidades serviriam de inspiração para vários cantos do mundo, inclusive o Brasil.

Ventos europeus e norte-americanos induziram dirigentes de algumas cidades brasileiras a se empenharem por melhorias em sua infraestrutura, urbanização e atividades de lazer. Um bom exemplo é Rio de Janeiro, que nesse período - início do século XX - viveu um intenso processo de reforma e saneamento, tendo como figura emblemática o prefeito Pereira Passos (Benchimol, 1990). Entre outras realizaçôes, o prefeito alargou ruas, construiu espaçosas avenidas, investiu em saneamento, bem como subvencionou os clubes de remo da cidade.

Fenômeno semelhante, mas com particularidades, aconteceu em Juiz de Fora/ MG. Na data de sua elevação de vila a município, 1850, a cidade chamava-se Santo Antônio do Paraibuna, nome que seria alterado somente em 1865. Durante o último quartel do século XIX, Juiz de Fora viveu o início de um período significativo de transformações econômicas, políticas, sociais e culturais (Andrade, 1987; Christo, 1994; Lessa, 1985).

De acordo com Maraliz Christo (op. cit., p.1), até a década de 1920, "Juiz de Fora é apontada como o centro cultural do Estado, seja pelo seu número de jornais e teatros, seja pela expressão de suas escolas e instituições culturais".

I. Anthony Giddens ( 199 | ) identifica a modernidade como um estilo, um costume de vida ou uma organização social que possui características próprias, tais como o ritmo veloz das mudanças e da comunicação, o sistema político do Estado-Nação, a transformação de produtos e serviços em mercadorias, bem como a crença no progresso e no poder da ciência.

Pro-Posições, Campinas, v. 22, n. 3 (66), p. 51-65, set./dez. 2011 
Entre o final do século XIX e as primeiras décadas do século XX, Juiz de Fora respirou ares do projeto de civilização da nação brasileira idealizado pelo pensamento republicano. Parte dos trabalhos sobre a história da Manchester mineira atrela esse desenvolvimento de Juiz de Fora ao modelo oferecido pelo Rio de Janeiro. A urbanização, a nova arquitetura, os novos hábitos dos cariocas teriam atravessado a estrada e influenciado diretamente os juiz-foranos.

Como cidade do Século XIX, Juiz de Fora não participa da cultura colonial mineira. A proximidade e o maior intercâmbio econômico e cultural com o Rio de Janeiro, assim como a luta política contra o predomínio da zona de Mineração, provocaram na cidade um maior cosmopolitismo, uma abertura mais acentuada, se a compararmos com o antigo centro do ouro (Christo, op. cit., p.1).

É evidente que o processo de urbanização e modernização de Juiz de Fora não foi simplesmente um desdobramento do que acontecia no Rio de Janeiro em período semelhante. Maraliz Christo (op. cit.) ressalta que foi organizado um projeto de modernização patrocinado por fazendeiros e capitalistas, que tinha como foco a industrialização de Juiz de Fora e também a necessidade de melhor controlar o espaço urbano e a população.

Victor Andrade de Melo (2001) identifica a adesão do povo carioca aos banhos de mar, à ginástica, ao turfe, ao remo e às atividades esportivas como uma tentativa de inscrição na cultura moderna que se desenvolvia entre o final do século XIX e o início do século XX.

Gilmar Mascarenhas de Jesus (1999) afirma que a receptividade da população carioca aos esportes e a outras práticas corporais na virada para o século XX foi significativa. Tal atitude se vinculava ao fato de estas representarem uma via para a vida saudável, sobretudo "ao fato de constituírem um elemento civilizador do ideário burguês importado da Europa, numa conjuntura em que ser moderno era desejar ser estrangeiro" (op. cit., p. 20).

Nossa pesquisa busca investigar como se deu esse processo de desenvolvimento das práticas corporais em Juiz de Fora e que discursos favoreceram a adesão da população juiz-forana a esse novo hábito entre 1876 e 1915 . No presente artigo, utilizamos como fonte o jornal $O$ Pharol, o mais importante periódico publicado na cidade entre 1870 e 1940.

\section{A Imprensa e o jornal O Pharol}

A imprensa foi parte fundamental do tempo histórico que chamamos de modernidade. As transformações políticas, culturais, sociais e econômicas do mundo em meados do século XIX e início do XX foram retratadas e discutidas em jornais 
e periódicos que fizeram circular informaçôes e novidades. Notícias, anúncios, cartas, notas, comentários, romances e fotografias passaram a ter cada vez mais espaço no cotidiano das cidades e das pessoas.

No Brasil, o jornal tornou-se o veículo de comunicação mais importante durante o século XIX, pois conseguia chegar a um número significativo de pessoas. Ainda que houvesse um contingente importante da população que não dominava a escrita e a leitura, a elite o prestigiava, e mesmo os iletrados tomavam conhecimento das notícias através de comentários, conversas e rodas de leituras.

Em Juiz de Fora, os primeiros jornais começaram a ser impressos por volta de 1870. Até então, circulavam na cidade os jornais publicados no Rio de Janeiro e na antiga capital da província de Minas Gerais, Ouro Preto.

De acordo com Paulino de Oliveira (1966), O Pharol foi fundado em Paraíba do Sul por Tomaz Cameron, em 1866, tendo sido transferido para Juiz de Fora em 1870. Em 1873, seu proprietário era Leopoldo Augusto de Miranda e seu chefe de redação, Georges Charles Dupin. O francês foi o introdutor do vapor como força motriz para máquinas de impressão em Minas Gerais e também foi proprietário do impresso, que teve outros donos e diferentes orientações políticas durante sua existência, até 1940.

O Pharol começou como semanário e assim permaneceu até 1873. Em 1874, passou a ser publicado em dois dias da semana, passando a jornal diário em 1885. Antes de 1930, nenhum jornal da cidade circulou com mais de quatro páginas, a não ser em edições extraordinárias, organizadas paulatinamente. O Pharol foi o mais importante periódico desse período e é até hoje uma fonte indispensável de pesquisa para aqueles que desejam analisar a história de Juiz de Fora.

\section{Práticas corporais no jornal O Pharol}

As práticas corporais e as diversões identificaram-se como símbolos da modernidade. E temos aqui dois conjuntos principais de argumentos presentes naquele momento. De um lado, o discurso médico em favor da saúde, que veio favorecer a expansão dos métodos de ginástica. De outro, a dimensão do espetáculo, as vivências lúdicas e divertidas que proporcionavam o esporte, o circo, as danças, as apostas, o teatro, o cinema, os bares e os salóes, entre outros.

As décadas de 1880-1890 testemunharam novidades de importância fundamental para o futuro: novos modos de aquecimento, iluminação e transporte; melhor acesso à água e ao lazer, ao exercício, à informação e aos lugares distantes. Telégrafo e telefones; máquinas de escrever e elevadores; transporte público de massa e esse maravilhoso cavalo individual [...] tudo conquistas do fin de siècle (Weber, 1988, p. 13).

Pro-Posiçôes, Campinas, v. 22, n. 3 (66), p. 51-65, set./dez. 2011 
As mudanças na organização e na estruturação de Juiz de Fora, a abertura de ruas, os projetos de saneamento, a efetivação de códigos de postura, o aparecimento de cafés e teatros sugerem que a cidade passou a respirar ares mais modernos, especialmente a partir do último quartel do século XIX. Em nossa pesquisa, interessa-nos perceber como se deu o desenvolvimento das práticas corporais nesse período ${ }^{2}$.

As práticas corporais estavam presentes no cotidiano de Juiz de Fora, e a elas - principalmente à ginástica, aos esportes e às lutas - eram feitas constantes referências no jornal $O$ Pharol.

A notícia da venda de aparelhos completos de ginástica em Juiz de Fora diznos bastante. Sua publicação, em 15/10/1880, é bem anterior ao período em que supúnhamos que a prática da ginástica tivesse sido desenvolvida na cidade. Pesquisas anteriores apontavam a fundação do Colégio Granbery (1889) e dos Grupos Escolares (1907), bem como a criação do Clube Ginástico de Juiz de Fora (1909), como momentos fundadores do desenvolvimento da ginástica em terras juiz-foranas. Sem dúvida, essas instituições tiveram importância fundamental nesse processo, mas importa perceber que, já em 1880, a ginástica era indicada pelo Pharol como prática corporal para adultos e crianças.

A esgrima, considerada na época como um exercício ginástico, também aparece no $O$ Pharol, ofertada à população:

Abre-se a 1 de Junho, á rua do Imperador, nesta cidade, uma aula de esgrima, dirigida por um ex-official do exercito francez. A aula funccionará ás quintas-feiras e domingos. Achão-se, desde já, abertas as inscripções (O Pharol, 31 maio 1883, p.2).

Até as primeiras décadas do século XIX, a prática regular dos exercícios ginásticos era uma realidade quase exclusiva das instituiçôes militares. Ela foi estendida ao meio civil e, por conseguinte, às escolas, a partir da revelação de seu caráter científico, de sua afirmação como parte significativa dos novos códigos de civilidade postos em circulação e de sua importância enquanto componente educativo. Esse foi um processo que percorreu todo o período oitocentista na Europa.

No Brasil, os exercícios ginásticos também faziam parte do treinamento fornecido pelo Exército e pela Marinha Imperial. Nesse meio, a prática regular da ginástica tinha como objetivos desenvolver as qualidades físicas - força, destreza e resistência - e os valores morais do soldado: coragem, caráter e hierarquia, preparando-o para o exercício das funçóes militares, principalmente para o combate. Do mesmo modo que nos países europeus, muito por sua influência em nossa cultura,

2. Entendemos por práticas corporais um conjunto de manifestações corporais, práticas físicas, realizadas com fins diversos, institucionalizadas ou não, e que podem ser resumidas em ginásticas, esportes, danças, jogos e lutas.

Pro-Posiçôes, Campinas, v. 22, n. 3 (66), p. 51-65, set./dez. 2011 
a ginástica passaria a ser considerada em terras brasileiras como uma atividade relevante à educação civil, a partir de sua identificação com o discurso científico, principalmente aquele produzido pelos médicos.

Na vertente de um projeto médico-higienista, os médicos brasileiros, ao longo do século XIX, realizaram a defesa da ginástica, considerada como um meio de controle social, de formação moral e disciplinar, de regeneração/aperfeiçoamento da raça, de construção/inculcação de um sentimento de identidade nacional, de desenvolvimento e aprimoramento do físico e da saúde. De acordo com Carmen Lúcia Soares (2001, p. 52), a ginástica era defendida a partir das finalidades de "regenerar a raça, promover a saúde, desenvolver a vontade, a coragem, a força, a energia de viver e, finalmente, desenvolver a moral".

Era comum, no jornal $O$ Pharol, a presença de notícias e anúncios de colégios. Em alguns deles, era ressaltada a presença da ginástica e sua importância para a saúde. Em 1910, por exemplo, localizamos uma referência a Escola Dona Maria do Carmo Menezes, instituição que havia investido na compra de materiais e equipamentos para a prática da ginástica. A escola, fundada pelo médico Eduardo de Menezes, tinha como finalidade especial desenvolver um trabalho profilático com relação à tuberculose.

Já se acham installados na Escola aparellhos de gymnastica, que farão della uma cousa inegualavel no Estado, mesmo em estabelecimentos oficiaes. Assim, vimos, ali ante-hontem, os seguintes apparelhos: três barras fixas, três barras paralelas, três cavallos, uma batuta de molas, quatro batutas pequenas, cinco colchōes para lutas, uma amarração de duas mesas, dois pares de estantes para pular, argolas, trapézios, cordas, duas escadas grandes, duas collocadas na parede com movimento automático; alteres de 5 até 100kilos, medidor de altura; um passo gigante, 100 garrafas de madeira, 100 ferros, 100 alteres pequenos, para exercícios flexíveis; quatro cadeiras para pyramides, tres obstáculos para corrida, um jogo para lança, uma gangorra: diversos aparelhos de nataçẫo, dois bancos para gymnastica sueca, varas para pulso de altura, um cavallete para equilíbrio e muitos outros diversos aparelhos (O Pharol, 12 ago. 1910, p. 1).

Como afirmamos anteriormente, a ginástica era defendida pelos médicos por seu caráter científico, racional, metódico e disciplinador. Mas outra vertente dos exercícios ginásticos também estava presente no jornal $O$ Pharol. Falamos da ginástica dos circos, instituiçôes que frequentemente se apresentavam com sucesso em Juiz de Fora, como revela a leitura desse periódico.

Um dos aspectos mais comentados nas apresentaçōes dos circos era o exímio trabalho corporal apresentado pelos artistas: as acrobacias no ar, os números de 
equilíbrio, os saltos, a flexibilidade, o risco, a beleza dos gestos e a estética dos corpos torneados exibidos na malha colante.

Effectuou-se no dia 20, o beneficio do Sr. Pery, director da companhia Luzo-Brazileira [...] Uma novidade da noite foi o duble salto mortal, executado pelo Sr. Paraná que é o primeiro artista brazileiro por quem vimos fazer semelhante trabalho (O Pharol, 24 set. 1982, p. 2).

Carmen Soares (1998) demonstra que a ginástica teve como fontes inspiradoras os movimentos de acrobatas e funâmbulos. Todavia, a partir da influência do discurso científico sobre o corpo e o exercício, tais movimentos passaram a ser criticados como nocivos à saúde e à moral.

A ginástica, então, passa a ser apresentada como produto aca-
bado e comprovadamente científico. Radicaliza, no universo
das práticas corporais existentes, a visão de ciência como ati-
vidade humana capaz de controlar, experimentar, comparar
e generalizar as açôes de indivíduos, grupos e classes. [...] A
ginástica científica se apresenta como contraponto aos usos
do corpo como entretenimento, como simples espetáculo,
pois trazia como princípio a utilidade de gestos e a economia
de energia (Soares, 1998, p. 23).

É interessante pensar nas relações estabelecidas entre a ginástica praticada nos circos e aquela defendida pelos médicos em Juiz de Fora. De um lado, o discurso científico e racional em favor da saúde. De outro, os perigos e os exageros dos movimentos e das articulaçôes. De certa forma, isso se resolvia quando os próprios médicos argumentavam que aquela ginástica circense era espetáculo-diversão. Já na escola, a ginástica possuía o sentido do trabalho; portanto, deveria ser metódica e útil.

Em 1910, O Pharol registrou a fundação do Clube Ginástico de Juiz de Fora, instituição importante, que desenvolveu, na cidade, a ginástica fora das escolas, para todas as idades:

Fundou-se, nesta cidade, em 10 de agosto de 1910, o Turnerschaft Club Gymnastico de Juiz de Fora, tendo por fim o desenvolvimento de forças corporaes e a destreza e a fortalecer a saúde de seus associados por meio de exercícios gymnasticos regulares e disciplinados, excitando assim também suas qualidades moraes como sejam circumspecção e coragem, dando ensejo aos seus associados para cultivar e fortificar o ardor da gymnastica (O Pharol, 12 ago. 1910, p. 1). 
Se a ginástica racional e científica manteve relaçóes estreitas com a ambiência moderna, outra prática corporal, o esporte, também apresentou conexōes importantes com aquele cenário e, talvez até mais do que a ginástica, articulou-se com o ideário inovador da modernidade em sua perspectiva de desafio, disputa, velocidade, comparação de resultados, exposição do corpo e prazer:

A prática esportiva estava diretamente articulada com os sentidos e significados de um novo modus vivendi que incluía o desafio, o movimento, a exposição corporal, a velocidade, a busca do prazer e da excitação, a crença na ciência e no progresso, a idéia de multidão, a formação de uma cultura urbana que também dialoga com o gosto das camadas médias e populares (Melo, 2006, p. 202).

Victor Melo (2001) afirma que, além de afirmar-se enquanto uma prática física, o esporte promove um espetáculo de corpos, gestos, formas e vozes que leva milhares de pessoas aos estádios, às praças, às ruas, aos hipódromos e às regatas, pelo prazer de assistir, de torcer e de divertir-se.

Outra prática esportiva então desenvolvida em Juiz de Fora era a corrida. As corridas a pé gozavam de prestígio no Rio de Janeiro ao final do século XIX. Eram realizadas provas em agremiaçōes como o Club Athletico Brazileiro e a Real Sociedade Club Gymnastico Portuguez. Alguns desses clubes começaram a organizar também provas de ciclismo. Em 1885, por exemplo, "o Sport Club Villa Izabel anunciava grandes corridas a pé e em velocípedes em seu prado". (Schetino, 2007, p. 140)

Em 1886, O Pharol noticiou a iniciativa de alunos de um colégio de Juiz de Fora, o São Salvador, de fundar o Club Atletico São Salvador. Era um clube de corridas a pé, criado com o objetivo de realizar provas abertas à população juizforana. O clube organizou quatro corridas no ano de 1886, nos meses de março, abril, maio e agosto. Todas as provas foram noticiadas pelo jornal que, por meio do seu editor, fez comentários elogiosos às corridas.

É interessante notar a fundação do clube pelos estudantes, dentro de um espaço escolar. Só mais recentemente as pesquisas no campo da História da Educação Física trataram da presença do esporte nas escolas brasileiras do século XIX. Até há pouco tempo, concebíamos que a ginástica fosse o único conteúdo desenvolvido nessas instituições. A informação sobre o Club Atlético São Salvador afirma a importância do esporte no Brasil do fim do século XIX, bem como nos leva a refletir sobre os efeitos que esse saber desenvolveu na cultura escolar.

As corridas também foram organizadas em Juiz de Fora na perspectiva de um espetáculo para a população. Em agosto de 1886, exibiu-se na cidade a Família Bargossi, de origem italiana, cujo destaque era o corredor Achille Bargossi, conhecido na Europa como o Homem locomotiva. Bargossi se apresentou em diversos 
países da Europa e da América do Sul, sempre desafiando outros corredores e até animais. Treinou sua mulher para provar a eficiência do seu método, que buscou introduzir no exército italiano ${ }^{3}$. Após sua morte, sua mulher e seu filho continuaram percorrendo o mundo e promovendo espetáculos de corrida, como o apresentado em Juiz de Fora. A exibição ocorreu no Hotel Renaissance, onde foi construído um jardim para possibilitar a apresentação da corrida. O hotel localizava-se no Largo da Estação, uma das regiōes mais movimentadas de Juiz de Fora à época. O espetáculo contou ainda com banda de música, e o público poderia desafiar Madame Bargossi para um duelo nas provas de corrida.

Se a velocidade proporcionada pelas corridas a pé e o desafio e a competição desenvolvida nas provas e nas exibições chamaram a atenção dos juiz-foranos, também o ciclismo se constituiu como atividade esportiva desenvolvida na cidade.

Segundo Eugene Weber (op. cit.), criados por volta de 1863, os velocípedes foram uma atração que atendeu aos anseios das elites: distinção, status e diversão. Os irmãos Pierre e Ernest Michaud ficaram conhecidos no mundo todo pela invenção. Com o passar dos anos, os velocípedes foram sendo modificados e se transformaram nas bicicletas.

De acordo com Victor Melo (2006), no início do século XX, a bicicleta já tinha se tornado um popular meio de lazer e transporte, e as primeiras competiçóes também já eram organizadas.

Um dos motivos que explicam a ascensão e a popularidade do esporte nos finais do século XIX e no início do XX é a sua capacidade de permitir novas vivências e experiências. No caso do ciclismo, podemos pensar no impacto causado pela velocidade, pela sensação de romper o ar e na liberdade alcançada pela possibilidade de deslocar-se pelas próprias forças.

Considerado naquele momento como "moderníssimo gênero de sport", o ciclismo passou a fazer parte das diversōes que cresciam em importância para o público das cidades, em especial para as elites, que se tornaram amadoras desse "interessante gênero de sport", considerado uma das "diversões mais finas, mais elegantes e mais úteis”. (Rodrigues, 2006, p.107).

O jornal O Pharol noticiou, em 28/08/1901, a realização de uma corrida de bicicletas no trajeto compreendido entre o bairro Alto dos Passos e a Cervejaria Weiss, localizada no bairro São Pedro. Outra corrida também foi noticiada na edição de 30 de agosto de 1901, na página 1.

3. Para maiores informações, ver biografia de Achille Bargossi. Disponível em: <www.fidal. it/files/bargossi.pdf>. Acesso em: 10 mar. 2010. 
Se as corridas de bicicletas proporcionavam experiências positivas e emocionantes aos ciclistas e ao público que assistia às corridas, a invenção, também utilizada para o transporte, causava acidentes na cidade: "Sempre os ciclistas. Crianças atropeladas - Ante-ontem em vertiginosa correria, passava um cyclista pela rua Santa Rita, dando ocasião a um lamentavél desastre" (O Pharol, 13 jun. 1911, p.1).

O desafio, a demonstração de força e as apostas marcaram outra prática corporal desenvolvida em Juiz de Fora: as lutas. Encontramos, em vários exemplares d' $O$ Pharol, anúncios de lutas que aconteciam na cidade, sempre na especialidade luta romana. Os eventos aconteciam nos circos, como parte do programa, e também em locais específicos e improvisados, como o Pavilhão Hespanhol. O espetáculo consistia de uma destemida luta ente um homem e uma junta de bois. Para complementar o espetáculo, uma banda de música italiana tocava um vasto repertório.

Em maio de 1882, O Pharol apresentou diversos anúncios e relatos sobre um exímio lutador que estava de passagem por Juiz de Fora. Tratava-se de Máximo Rodrigues - para o jornal, "um verdadeiro Hércules". Ele promoveu espetáculos de lutas contra adversários humanos e contra animais:

Realizou-se no dia 25 a luta annunciada, contra uma junta de bois. Apezar da força dos animaes, apezar mesmo de terem sido aguilhoados com vontade, só conseguirão partir o cambão que prende á canga: o Hercules ficou immovel! ( $O$ Pharol, 28 maio 1882, p.1).

O "Hércules" ainda utilizava periódico como meio de desafiar adversários e chamar a atenção dos leitores para o espetáculo:

Lutador - O abaixo assignado, sciente da proposta do Sr. Angelo Fariña, para a luta romana, declara ao mesmo senhor, que está prompto a acceital-a e nas condiçōes precisas, podendo ter luta sabbado próximo. Antes não é possível, visto como na quinta-feira tem de fazer diversos exercícios, entre elles a luta contra os bois, que demandão grande força. Póde o Sr. Fariña entender-se pessoalmente com o abaixo assignado. Maximo Rodriguez (O Pharol, 23 maio 1882, p.2).

As lutas, com o passar dos anos, desapareceram das páginas do jornal. Elas foram noticiadas e comentadas no Pharol entre 1876 e 1885, não sendo encontradas mais notícias nos anos posteriores. Marilita Rodrigues (op. cit.) estudou as práticas corporais em Belo Horizonte e afirma que, na cidade, as lutas romanas deram lugar ao boxe. Em Juiz de Fora, até o ano de 1915, localizamos apenas duas notícias no Pharol sobre o boxe, ambas anunciando um combate realizado em dezembro de 1914 entre o campeão mineiro e um italiano. 
Box - Realiza se hoje, á 1 1 1 2 da tarde no cinema Pharol, o "match" de box entre Francisco Anelli campeão italiano (desafiante) e José Fontes. Campeão mineiro (desafiado) [...] Antes do box haverá exhibições cinematographicas. $(O$ Pharol, 27 dez.1914, p.4)

O futebol, prática esportiva que goza hodiernamente de muitos adeptos no mundo, também apareceu nas páginas do Pharol. A história deste esporte no Brasil é ainda farta em controvérsias e embates, talvez pela importância que o futebol assumiu em nossa cultura. As pessoas mais próximas ao esporte reconhecem Charles Miller como o pai do futebol brasileiro, aquele que, ao retornar da Inglaterra, em 1894, após estudos, chegou a São Paulo com duas bolas de futebol, dois jogos completos de uniformes, uma bomba de ar e uma agulha. Menos conhecido, mas figura também sempre lembrada, é Oscar Cox, carioca que estudou na Suíça, cuja iniciativa possibilitou a introdução do futebol no Rio de Janeiro (Santos Neto, 2002).

É evidente que Charles Muller e Oscar Cox foram importantes na história do Brasil, mas determinados estudos sobre o tema cristalizaram esses nomes e o ano de 1894 como verdades absolutas. Analisemos o assunto a partir do texto de João Máximo (1999, p.181):

Esqueçamos os nascimentos não documentados [...] o primeiro match em terra brasileira promovido por Charles Miller - com uma daquelas bolas, num terreno baldio da várzea do Carmo, entre as ruas Santa Rosa e do Gasômetro - na manhã de domingo, 14 de abril de 1895 .

A perspectiva histórica que adotamos em nosso trabalho nos impede de esquecer os demais possíveis nascimentos do futebol em terras brasileiras. E muito nos importam as pistas, os indícios e os vestígios de práticas desse esporte anteriores a Charles Muller e Oscar Cox. Mas nossa análise não se volta para perseguir as origens do futebol brasileiro; é importante frisar esta afirmação, pois em Juiz de Fora convivemos com a ideia de que o Colégio Granbery teria sido palco da primeira partida do esporte, no ano de 1893 :

Inaugurou Foot-ball and Tennis. O primeiro field Day realizou-se em 24 de junho de 1893 , com saltos, corridas, indianclubs, tennis, football entre gregos e troianos. Essa frase está no primeiro livro de Atas do Granbery. O que era aparentemente uma afirmação simples de nosso primeiro reitor, John McPhearson Lander, ganha destaque, se lembrarmos que o primeiro jogo de futebol no Brasil foi realizado em 15 de abril de 1895 entre funcionários de empresas inglesas 
que atuavam em São Paulo. Significaria arriscar dizer que, com base nos documentos históricos preservados até hoje, a primeira partida de futebol no Brasil ocorreu na verdade aqui no Granbery, em 1893 ( $O$ Granberiense, ano 76, n. 1, abr. 2007).

Não localizamos no Pharol comentários ou notícias a respeito do futebol em Juiz de Fora antes dos primeiros anos do século XX. Em 27 de novembro de 1904, uma nota destacava a fundação do Athletic Club Juiz de Fora, clube que organizava jogos para seus associados num terreno de propriedade de Manoel Honório de Campos.

Em 12 de março de 1905, o jornal noticiou a primeira partida realizada pelos sócios do Athletic Club Juiz de Fora. No mesmo ano, O Pharol deu notícia das partidas que o Athletic passou a realizar com outras equipes da cidade, como o Granberyense, time do Colégio Granbery.

Ainda em 1905, localizamos n'O Pharol interessante matéria redigida por autor desconhecido, que assina "L.":

Esta agora em moda em nossa cidade o foot-ball. Dentre os muitos jogos athleticos, affirmam-me que esse é um dos mais encantadores, e um dos mais praticados, actualmente, no Sport carioca e paulistano. Toda gente esta farta de saber que esses divertimentos são recommendados pelos higienistas e que eles completam a educação de um gentleman que se preza. Eu prefiro passar o meu domingo de folga com os meus melhores amigos: os livros. Nem por isso, entretanto, deixo de ser o primeiro a reconhecer que o atletismo é um elemento necessário ao desenvolvimento physico do individuo e que o foot-ball é um dos muitos meios conhecidos para se quebrar uma perna com enthusiasmo e alegria. Mas os moços não se deixam levar por semelhante temor e, aos domingos, já se sabe: tomam, em palreiro bando, o bonde da fabrica e vão ter á Manoel Honorio, onde passam deliciosas tardes de folguedo, jogando bola, que ainda é um jogo innocente, pois podiam fazer cousas muito peior se jogasse as cartas a tanto por tento. Outros phantasmas que me fazem fugir a sete léguas do foot-ball são os nomes arrevesados com que os foot-ballers se entendem. Além dos movimentos ágeis, dos saltos, das piruetas que devem empregar os que exercitam esse sport, tem de pôr em acção também a gymnastica da língua para pronunciar os difíceis nomes dos que tomam parte no match [...]. Divirtam-se, rapazes, e deixem-me, a mim, com o meu sossego, o meu viver sosinho, o meu anacorethismo e os meus livros adorados, esses que me querem tanto, e 
que me distraem, e que me educão e que me instruem. ( $O$ Pharol, 01 ago. 1905).

O autor fala sobre o futebol como uma moda que havia chegado a Juiz de Fora, um dos jogos atléticos mais praticados no Rio de Janeiro e em São Paulo. As práticas corporais estavam em moda nesse momento histórico, e o futebol começava sua trajetória de sucesso entre os brasileiros.

L. diz compreender a validade do futebol como elemento da educação do gentleman e como lazer recomendado pelos médicos; ou seja, notamos aqui que esporte e saúde aparecem atrelados, o que, sem dúvida, ajuda a explicar a difusão das práticas esportivas em terras brasileiras.

Interessante ainda notar no depoimento as representaçôes que acompanharam durante tempos o futebol, como sua dimensão perigosa e violenta, "um dos muitos meios conhecidos para se quebrar uma perna com enthusiasmo e alegria". $\mathrm{Na}$ época, antes o futebol, uma prática saudável, ainda que perigosa à saúde, do que o perigo e a imoralidade do vício dos jogos de cartas. Juiz de Fora começava a receber equipes de fora da cidade para as disputas do futebol. Em 24 de novembro de 1907, localizamos a notícia de que o Granberyense havia convidado um time de Barbacena para um jogo. A equipe Dr. Cunha Foot-ball Club ficaria hospedada num dos principais hotéis da cidade, custeada pelo Granbery, e os jogadores seriam recebidos na estação pela banda de música do colégio. A notícia revela ainda que a partida seria realizada num ground ao lado da alfândega, outro local organizado na cidade para a prática do futebol.

Em 28 de novembro de 1907, uma extensa matéria detalhou a partida de futebol realizada entre o Granberyense e a equipe de Barbacena. Foi a primeira matéria escrita com tantos detalhes sobre um jogo ocorrido em Juiz de Fora: nomes das posições, fundamentos técnicos, táticos, jogadores. Vale ainda perceber a alusão que o jornalista faz ao público que assistia à partida e ao seu caráter de disputa/combate, o que denota a faceta do futebol e do esporte em sua dimensão competitiva.

Foot-Ball - [...] As 4horas e meia, dado o signal pelo referee Sr. Alfredo Guedes, os jogadores tomaram suas respectivas posições e deram principio ao jogo os fowards granberyenses, aos quaes coube por sorte o kick inicial. O primeiro ataque foi fortíssimo. Os fowards de ambos os lados luctavam com denodo e a bola pairava no meio do ground. Em dado momento, Orlando Pires, center-foward granberyense toma a bola, passa-a para os companheiros e assim, de passe a passe, levam-na até á boca do goal, donde é repelida por um enorme strik dado pelo goal-kepper Cobuci do Dr. Cunha Foot-ball Club. Uma prolongada salva de palmas coroou a brilhante defesa [...]. Inicia-se o quarto kick. Logo no segundo ataque,

Pro-Posiçôes, Campinas, v. 22, n. 3 (66), p. 51-65, set./dez. 2011 
já mais fraco que os outros, Luiz Gomes avança com a bola para o goal inimigo e consegue vasa-lo apezar da resistência hercúlea apresentada pelo goal-kepper Cabuci. Dez minutos depois terminava o jogo, entre os apllausos dos espectadores, sahindo o Club Athletico Granbeyense vencedor por quatro goals a um feito pelos barbacenenses ( $O$ Pharol, 28 nov. 1907 , p.1).

Outras instituições educativas de Juiz de Fora, além do Colégio Granbery, também começaram a interessar-se pelo futebol e formaram equipes. Esses jogos passaram a ser comuns na cidade a partir de 1913:

Football: Realizou-se ontem à tarde, ground da Academia do Comércio, um match de football entre os clubs "Ordem e Progresso" e "Machado Sobrinho", este do Collégio Lucindo Filho e aquelle do primeiro referido estabelecimento de ensino. (O Pharol, 31 maio 1913, p.2).

As notícias sobre o futebol começaram a ser frequentes a partir do final da década de 1900. O futebol tomou conta das notícias que $O$ Pharol publicava sobre as práticas corporais. A cidade recebia equipes argentinas para a disputa de jogos, o futebol organizava-se nos bairros que davam nome aos times e eram várias as notícias de fundação de clubes: New Foot-Ball Club, Halley Foot-Ball Club (1910), Club Sportivo, Tupynambás (1911), Tupi Football Club (1912).

4. Considerações finais

O presente artigo procurou analisar o desenvolvimento das práticas corporais em Juiz de Fora, entre 1876 e 1915, através do jornal O Pharol. Nesse período, a cidade passou por um intenso processo de modernização e, como em outras cidades brasileiras, as práticas corporais começaram a ganhar importância na sociedade da época.

A ginástica e os esportes estiveram presentes nas páginas d'O Pharol entre $1876 \mathrm{e}$ 1915. Incentivadas por médicos, devido a sua relação positiva com a saúde ou ainda por seu caráter espetacular, tais práticas corporais caíram no gosto da população juiz-forana e passaram a ocupar lugar relevante em seu cotidiano.

A cidade de Juiz de Fora alterou sua face entre 1876 e 1915. Uma nova forma de organização urbana aflorou, e as camadas médias da sociedade fizeram do espaço público da cidade lugar de lazer e entretenimento. E as práticas corporais, junto com as práticas de lazer, ganharam relevância nesse processo. Elas se apresentaram como marcas de um novo modus vivendi, articulando-se com este por meio da espetacularização do corpo, da vivência do prazer e da valorização da estética corporal.

Pro-Posições, Campinas, v. 22, n. 3 (66), p. 51-65, set./dez. 2011 


\section{Referências bibliográficas}

ANDRADE, S. M. B. Classe operária em Juiz de Fora: uma história de lutas (1912-1924). Juiz de Fora: EDUFJF, 1987.

BENCHIMOL, J. L. Pereira Passos: um Haussmann tropical. Rio de Janeiro: Prefeitura Municipal do Rio de Janeiro; Carioca 11, 1990.

CHRISTO, M. de C. V. Europa dos pobres - o intelectual e o projeto educacional dominante em Juiz de Fora na belle époque mineira. Juiz de Fora: EDUFJF, 1994.

GIDDENS, A. As consequências da modernidade. São Paulo: UNESP, 1991.

JESUS, G. M. de. Do espaço colonial ao espaço da modernidade: os esportes na vida urbana do Rio de Janeiro. Scripta Nova Revista Electrónica de Geografía y Ciencias Sociales — Universidad de Barcelona, Barcelona, n. 45, 1 ago. 1999. Disponível em: <http://www. ub.es/geocrit/sn-45-7.htm>. Acesso em: 04 ago. 2008.

LESSA, J. Juiz de Fora e seus pioneiros (do caminho novo à Proclamação). Juiz de Fora: EDUFJF, 1985.

MÁXIMO, J. Memórias do futebol brasileiro. Estudos Avançados, São Paulo, v. 13, n. 37, set./dez. 1999.

MELO, V. A. de. Cidade sportiva: primórdios do esporte no Rio de Janeiro. Rio de Janeiro: Relume Dumará; FAPERJ, 2001.

MELO, V. A. de. Cinema e esporte: diálogos. Rio de Janeiro: Aeroplano. 2006.

O GRANBERIENSE, Juiz de Fora, ano 76, n.1, abr. 2007.

OLIVEIRA, P. A imprensa em Juiz de Fora antes de 1930. Disponível em: <http://www. ihgjf.com.br>. Texto originalmente publicado em 1966. Acesso em: 5 out. 2009.

RODRIGUES, M. A. A. Constituição e enraizamento do esporte na cidade: uma prática moderna de lazer na cultura urbana de Belo Horizonte (1894-1920). Tese (Doutorado em Educação) - Universidade Federal de Minas Gerais, UFMG, Belo Horizonte, 2006.

SANTOS NETO, J. M. Visão do jogo: primórdios do futebol no Brasil. São Paulo: Cosac \& Naify, 2002.

SCHETINO, A. M. Do tour de France ao velódromo nacional: o ciclismo em Paris e no Rio de Janeiro na transição dos séculos XIX e XX. In: MELO, V. A. de (Org.). História comparada do esporte. Rio de Janeiro: Shape, 2007. p. 137-148.

SOARES, C. L. Imagens da educação no corpo: estudo a partir da ginástica francesa no século XIX. Campinas: Autores Associados, 1998.

SOARES, C. L. Imagens da educação no corpo. 2. ed. Campinas: Autores Associados, 2001.

WEBER, E. J. França fin-de-siècle. São Paulo: Companhia das Letras, 1988.

Recebido em 28 de março de 2011 e aprovado em 27 de maio de 2011. 
